\title{
Widening of the Hadley Cell from Last Glacial Maximum to Future Climate
}

\author{
SEOK-WoO SON AND SEO-YEON KIM \\ School of Earth and Environmental Sciences, Seoul National University, Seoul, South Korea \\ SEUNG-KI MIN \\ School of Environmental Science and Engineering, Pohang University of Science and Technology, \\ Pohang, South Korea
}

(Manuscript received 18 May 2017, in final form 26 September 2017)

\begin{abstract}
The Hadley cell (HC) change from paleoclimate to future climate is examined by comparing coupled model simulations archived for the Paleoclimate Modeling Intercomparison Project phase 3 (PMIP3) and phase 5 of the Coupled Model Intercomparison Project (CMIP5). Specifically, HC width and strength are evaluated using 100-yr equilibrium simulations for the Last Glacial Maximum (LGM), preindustrial (PI), and extended concentration pathway 4.5 (ECP4.5) conditions. Where available, ECP8.5 simulations are also examined to increase the sample size. All models show a systematic widening of the HC from the LGM to the PI and to the ECP4.5 and ECP8.5 simulations. Such widening, which is found in both hemispheres with more robust change in the Southern Hemisphere ( $\mathrm{SH})$ than in the Northern Hemisphere $(\mathrm{NH})$, is significantly correlated with global-mean surface air temperature change and the associated static stability change in the subtropics. Based on the zero-crossing latitude of $500-\mathrm{hPa}$ mass streamfunction, about $4.5^{\circ}$ latitude widening of the $\mathrm{HC}$ results from global warming of $10^{\circ} \mathrm{C} . \mathrm{HC}$ strength also exhibits a systematic weakening in the NH. However, in the $\mathrm{SH}, \mathrm{HC}$ strength shows a rather minor change from LGM to ECP4.5 conditions because of the cancellation between $\mathrm{HC}$ weakening during the austral summer-fall and its strengthening during the spring. This result, which suggests no systematic relationship between $\mathrm{HC}$ width and strength changes, is discussed in the context of quasigeostrophic zonal-mean dynamics. Overall findings are also compared with recent studies that are based on transient climate model simulations.
\end{abstract}

\section{Introduction}

The Hadley cell (HC), a thermally direct circulation with a rising motion in the deep tropics and a sinking motion in the subtropics, is known to control hydroclimates in low latitudes and their long-term changes (e.g., Lau and Kim 2015). Recent studies have shown that its latitudinal width, that is, the distance from the Southern Hemisphere (SH) HC edge to the Northern Hemisphere (NH) HC edge, has increased in the last few decades (e.g., Seidel et al. 2008). Based on the zero-crossing latitude of $500-\mathrm{hPa}$ mass streamfunction, $\mathrm{HC}$ widening in various reanalysis datasets is $0.2^{\circ}-1.6^{\circ}$ lat decade ${ }^{-1}$ (e.g., Davis and Rosenlof 2012; Lucas et al. 2014). This contrasts with the HC-strength change that is not consistent among the datasets (e.g., Nguyen et al. 2013).

These trends, however, are somewhat uncertain partly because of insufficient observations and rather short

Corresponding author: Seok-Woo Son, seokwooson@snu.ac.kr reanalysis datasets. For example, the range of the HCwidth trend between different reanalysis datasets is an order of magnitude larger than its internal variability (Quan et al. 2014). To reduce such uncertainty and to identify its possible cause(s), state-of-the-art climate models have been extensively used. Among others, multimodel datasets archived for phase 3 (CMIP3; Meehl et al. 2007) and phase 5 of the Coupled Model Intercomparison Project (CMIP5; Taylor et al. 2012) have been widely used. Although coupled models significantly underestimate the $\mathrm{HC}$ trends estimated by reanalysis datasets (Johanson and Fu 2009; Garfinkel et al. 2015) mainly due to the internal variability (Allen et al. 2014; Mantsis et al. 2017), they qualitatively reproduce $\mathrm{HC}$ widening in the historical period. Most models also project that $\mathrm{HC}$ widening, along with its weakening, would continue in a warm climate (e.g., $\mathrm{Lu}$ et al. 2007; Hu et al. 2013; Seo et al. 2014). A series of attribution studies further documented that the observed and projected trends are primarily caused by the 
increasing greenhouse gas concentrations ( $\mathrm{Hu}$ et al. 2013; Tao et al. 2016) and the stratospheric ozone depletion (Son et al. 2009b; Min and Son 2013). Although anthropogenic aerosols have also likely affected HC width (Allen et al. 2012; Allen and Ajoku 2016), their impacts are not yet clear especially in the SH (Tao et al. 2016).

Unlike in the present and future climate, $\mathrm{HC}$ in the paleoclimate has not been well documented. A case in point is the $\mathrm{HC}$ during the Last Glacial Maximum (LGM), the latest cold period of the Ice Ages, about 21000 years ago. Since LGM orbital forcing and continental distribution are comparable to the present climate, atmospheric general circulation in this period can be directly compared with the current climate. Based on a robust widening of the $\mathrm{HC}$ from the present to future climate, it is particularly anticipated that the $\mathrm{HC}$ width in LGM condition is somewhat narrower than that in the preindustrial (PI) condition. This speculation was partly evaluated by the model simulations archived for the Paleoclimate Modeling Intercomparison Project phase 2 (PMIP2; Braconnot et al. 2007) and phase 3 (PMIP3; Braconnot et al. 2012). Although low-resolution models showed no change in HC properties from LGM to PI conditions (Otto-Bliesner and Clement 2004; Rind and Perlwitz 2004), many PMIP2 and PMIP3 showed a slightly narrower HC during the LGM as compared to that during the PI condition (Rojas 2013).

However, quantitative evaluation of LGM HC and its comparison to present and future climate have not been conducted. It is particularly unclear how $\mathrm{HC}$ width and its strength in a cold climate differ from those in a warm climate. Following Chavaillaz et al. (2013), who examined SH westerlies in the PMIP3 and CMIP5 models, this issue is addressed in the present study by comparing multimodel datasets archived for both PMIP3 and CMIP5. Unlike the previous studies that are mostly based on transient climate simulations, this study examines equilibrium simulations. Specifically, LGM, PI, and extended concentration pathway 4.5 (ECP4.5) simulations are analyzed. For ECP4.5 simulations, only the last 100 years (i.e., twenty-third century) are considered when the global-mean surface air temperature (hereafter simply SAT unless specified) reaches equilibrium (Meinshausen et al. 2011). When ECP8.5 simulations are available, they are also analyzed to increase the sample size.

By comparing the LGM, PI, ECP4.5, and ECP8.5 simulations, it is shown that the $\mathrm{HC}$ width increases from cold to warm climate. A systematic weakening of the $\mathrm{HC}$, mainly occurring in the $\mathrm{NH}$, is also found. These changes are related to SAT changes to identify possible relationships between the dynamic (or circulation) sensitivity to the equilibrium climate sensitivity. The relative importance of static stability and vertical wind shear changes in $\mathrm{HC}$ widening and weakening is also evaluated.

This paper is organized as follows. In section 2, PMIP3 and CMIP5 models analyzed in this study are briefly described. The definitions of $\mathrm{HC}$ edge and strength are also introduced. In section 3, zonal-mean temperature and mean meridional circulation anomalies in LGM, ECP4.5, and ECP8.5 simulations, against PI simulations, are briefly discussed. The HC width and strength in each climate state are then described in section 4. Last, a summary and conclusions are presented in section 5 .

\section{Data and methods}

A total of six models provide LGM, PI, and ECP4.5 simulations. ECP8.5 simulations are also available in four models. They are listed in Table 1 by use of the acronyms provided in the Intergovernmental Panel on Climate Change (IPCC) Fifth Assessment Report (IPCC 2013). For all simulations, only the last 100 years are used. This allows a one-to-one comparison among the individual simulations. The only exception is the ECP4.5 simulation of FGOALS-g2, the data of which are available only up to 2275 . For this model, a $100-y r$ climatology is constructed by averaging the 75 years from 2201 to 2275. All other ECP4.5 and ECP8.5 simulations are analyzed for the period of 2201-2300.

It should be noted that the twenty-third century in ECP8.5 simulations is not fully in an equilibrium state. In this scenario, SAT slowly increases even in the twenty-third century, because greenhouse gas concentrations and the related radiative forcings are designed to be stabilized around 2250 (Meinshausen et al. 2011). However, SAT change in the twenty-third century is rather minor and net radiative forcing in 2201 is not dramatically different from that in 2300 (Meinshausen et al. 2011). It is therefore reasonable to assume that ECP8.5 experiments reach a quasi-equilibrium state in the twenty-third century.

As summarized in Table 1, each model has a different horizontal resolution. It ranges from a $0.9^{\circ} \times 1.25^{\circ}$ resolution (CCSM4) to a $2.8^{\circ} \times 2.8^{\circ}$ resolution (MIROCESM). To reduce the uncertainty associated with different data resolutions, all model outputs are first interpolated into the common resolution of $2.5^{\circ}$ latitude $\times$ $2.5^{\circ}$ longitude. In the vertical, they are log-linearly interpolated into 17 pressure levels as in the National Centers for Environmental Prediction (NCEP)-National Center for Atmospheric Research (NCAR) reanalysis data (NNR; Kalnay et al. 1996). A multimodel mean $(\mathrm{MMM})$ is then constructed by averaging these interpolated data across all available models. For reference, 
TABLE 1. The PMIP3 and CMIP5 models used in this study. (Expansions of acronyms are available online at http://www ametsoc.org/PubsAcronymList.)

\begin{tabular}{|c|c|c|}
\hline Model & $\begin{array}{l}\text { Atmospheric resolution } \\
(\text { lat } \times \text { lon })\end{array}$ & Experiments \\
\hline CCSM4 & $0.9^{\circ} \times 1.25^{\circ}$ & $\begin{array}{l}\text { LGM, PI, ECP4.5, } \\
\text { and ECP } 8.5\end{array}$ \\
\hline CNRM-CM5 & $\begin{array}{l}1.4^{\circ} \times 1.4^{\circ}(\mathrm{T} 85 \\
\text { spectral resolution })\end{array}$ & $\begin{array}{l}\text { LGM, PI, ECP4.5, } \\
\text { and ECP8.5 }\end{array}$ \\
\hline FGOALS-g2 & $2.8^{\circ} \times 2.8^{\circ}$ & LGM, PI and ECP4 \\
\hline GISS-E2-R & $2^{\circ} \times 2.5^{\circ}$ & $\begin{array}{l}\text { LGM, PI, ECP } 4.5, \\
\text { and ECP8.5 }\end{array}$ \\
\hline IPSL-CM5A-LR & $1.9^{\circ} \times 3.75^{\circ}$ & $\begin{array}{l}\text { LGM, PI, ECP4.5, } \\
\text { and ECP } 8.5\end{array}$ \\
\hline MIROC-ESM & $\begin{array}{l}2.8^{\circ} \times 2.8^{\circ}(\mathrm{T} 42 \\
\quad \text { spectral resolution })\end{array}$ & $\begin{array}{l}\text { LGM, PI and } \\
\text { ECP } 4.5\end{array}$ \\
\hline
\end{tabular}

$\mathrm{HC}$ properties in the NNR, European Centre for Medium-Range Weather Forecasts (ECMWF) interim reanalysis (Dee et al. 2011), and Japanese 55-year Reanalysis (Ebita et al. 2011) datasets are also analyzed. Their multidata mean from 1980 to 2010 is presented for a qualitative comparison.

Both $\mathrm{HC}$ width and strength are quantified by using a $500-\mathrm{hPa}$ mass streamfunction $\psi 500$. In this metric, the poleward edge of the $\mathrm{HC}$ in each hemisphere is determined by the zero-crossing latitude of $\psi 500$, and the total width is defined by the distance between the $\mathrm{SH}$ and $\mathrm{NH} \mathrm{HC}$ edges. Likewise, the strength of the $\mathrm{HC}$ is simply quantified by the maximum value of $|\psi 500|$ (absolute $\psi 500$ ) within the HC. Note that to match the sign between the two hemispheres, absolute $\psi 500$, instead of raw $\psi 500$, is used. Here $\psi 500$ is calculated as below:

$$
\psi 500=\frac{2 \pi a \cos \varphi}{g} \int_{10 \mathrm{hPa}}^{500 \mathrm{hPa}} \overline{[v]} d p,
$$

where $a$ is the radius of Earth, $\varphi$ is the latitude, $g$ is the gravitational acceleration, and $v$ is the meridional wind The square brackets and overbar denote the zonal mean and the time mean, respectively. For the time mean, either the long-term seasonal mean or annual mean is applied. In Eq. (1), the upper limit of vertical integration is set to $10 \mathrm{hPa}$. Although not shown, overall results are not sensitive to the choice of upper limit.

It is well documented that $\psi 500$ is directly related with the eddy momentum flux. The time-mean zonal-mean zonal momentum equation in the quasigeostrophic zonal-mean dynamics can be written as follows:

$\frac{\partial \overline{[u]}}{\partial t}=-\frac{1}{a \cos ^{2} \varphi} \frac{\partial \overline{\left[u^{*} v^{*}\right]} \cos ^{2} \varphi}{\partial \varphi}+f \overline{[v]}-\frac{\overline{[u]}}{\tau}=0$,

where the asterisk denotes the deviation from the zonal mean, $u$ is the zonal wind, $f$ is the Coriolis parameter, and $\tau$ is the time scale of surface friction. If one integrates this equation from 10 to $500 \mathrm{hPa}$ and applies Eq. (1), $\psi 500$ can be associated with the vertically integrated eddy momentum flux divergence:

$$
\psi 500=\frac{2 \pi}{g f} \frac{1}{\cos \varphi} \int_{10 \mathrm{hPa}}^{500 \mathrm{hPa}} \frac{\partial \overline{\left[u^{*} v^{*}\right]} \cos ^{2} \varphi}{\partial \varphi} d p
$$

This equation indicates that $\psi 500$ is determined by the eddy momentum flux divergence in the upper troposphere. The HC edge, that is, the zero-crossing latitude of $\psi 500$, is then located at the latitude of the maximum eddy momentum flux in the NH subtropics or at its minimum in the SH subtropics. Equation (3) further suggests that the $\mathrm{HC}$ strength, defined by maximum $|\psi 500|$, is controlled by the intensity of the eddy momentum flux divergence. Note here that while $\mathrm{HC}$ edge is set by the latitude of the maximum (or minimum in the $\mathrm{SH}$ ) eddy momentum flux in the $\mathrm{NH}$, its strength is determined with the maximum eddy momentum flux divergence. This implies that $\mathrm{HC}$ width and its strength do not necessarily change together. Note also that although quasigeostrophic assumption holds at the $\mathrm{HC}$ edge $\left(\sim 30^{\circ}\right.$ latitude) where local Rossby number is negligible, it does not work in the deep tropics where angularmomentum-conserving circulation becomes important (e.g., Schneider and Bordoni 2008). This implies that the $\mathrm{HC}$ strength is not simply determined by eddy momentum flux alone.

The $\psi 500$ metric is not the only way to define the HC. For example, the $\mathrm{HC}$ edge can be also detected using the maximum sea level pressure (SLP) in the subtropics (e.g., Choi et al. 2014). Specifically, the latitude of the subtropical high (or ridge), which forms at the downward branch of the $\mathrm{HC}$, can represent the $\mathrm{HC}$ edge. As discussed in Choi et al. (2014), this definition (hereafter the SLP metric) is dynamically related with the $\psi 500$ metric. Equation (2) can be integrated to the sea level instead of $500 \mathrm{hPa}$. If the poleward flow in the tropical upper troposphere is balanced by the returning flow near the surface, it becomes

$$
\overline{[u}_{\mathrm{SL}}=-\frac{\tau}{a \cos ^{2} \varphi} \int_{10 \mathrm{hPa}}^{\mathrm{SLP}} \frac{\partial \overline{\left[u^{*} v^{*}\right]} \cos ^{2} \varphi}{\partial \varphi} d p .
$$

By taking the geostrophic balance, the zonal-mean zonal wind at the sea level $\overline{[u}_{\mathrm{SL}}$ can be further related with the zonal-mean SLP field:

$$
{\overline{[u]_{\mathrm{SL}}}}_{-} \frac{1}{f} \frac{\partial \overline{[\mathrm{SLP}]}}{a \partial \varphi} .
$$

Equations (4) and (5) suggest that the latitude of the subtropical high, where zonal-mean SLP is at its 
maximum (or its latitudinal gradient is zero), is directly related with the column-integrated eddy momentum flux divergence. Since the eddy momentum flux is strongest in the upper troposphere, the HC edges derived from the $\psi 500$ and SLP metrics would be quantitatively similar in the $\mathrm{SH}$ where the zonal-mean quasigeostrophic dynamics works well. This conjecture is confirmed in the following section.

The above exercise suggests that $\mathrm{HC}$ properties are to a large extent modulated by the latitudinal distribution of the eddy momentum flux. In this regard, it is worthwhile to note that the eddy momentum flux does not explicitly appear in the linear baroclinic instability theory, although $\mathrm{HC}$ widening and weakening have been often related with linear baroclinicity change (e.g., $\mathrm{Lu}$ et al. 2007). It is instead organized in the decaying stage of the baroclinic eddy life cycle (e.g., baroclinic growth followed by barotropic decay; Simmons and Hoskins 1978). This suggests that the relationship between $\mathrm{HC}$ properties and baroclinicity changes is not necessarily linear.

\section{Temperature and zonal-mean circulation}

The $\mathrm{CO}_{2}$ concentration in LGM condition is approximately 185 ppmv (Braconnot et al. 2012). This is much lower than the $\mathrm{CO}_{2}$ levels in PI $(\sim 280 \mathrm{ppmv})$, ECP4.5 ( $\sim 540$ ppmv in 2250), and ECP8.5 conditions ( $\sim 2000$ ppmv in 2250; Meinshausen et al. 2011). This difference in $\mathrm{CO}_{2}$ concentrations (and other greenhouse gas concentrations) indicates that SAT in LGM condition is much colder than that in ECP scenarios. Quantitatively, the LGM SAT is about $4.5^{\circ} \mathrm{C}$ colder than the PI SAT, while twenty-third-century SATs in ECP4.5 and ECP8.5 scenarios are approximately $2.9^{\circ}$ and $9.0^{\circ} \mathrm{C}$ warmer than the PI SAT (Table 2). Note that in spite of the nonnegligible intermodel spread, the MMM temperature of each (quasi-)equilibrium state is very well separated. Such separation is more distinct in the northern high latitudes because of polar amplification (Figs. 1a-c). If one only considers the tropical-mean SAT averaged over $30^{\circ} \mathrm{S}-30^{\circ} \mathrm{N}$, its difference between the LGM and ECP4.5 simulations is only about $5.1^{\circ} \mathrm{C}$, smaller than the global-mean SAT difference of approximately $7.4^{\circ} \mathrm{C}$.

Here it is important to note that the SAT does not linearly change in response to $\mathrm{CO}_{2}$ concentration. For example, the SAT difference between the LGM and PI simulations, normalized by the $\mathrm{CO}_{2}$ difference, is approximately $4.5^{\circ} \mathrm{C}(95 \mathrm{ppmv})^{-1}$. This value is much larger than the difference between the ECP4.5 and PI simulations $\left[\sim 2.9^{\circ} \mathrm{C}(160 \mathrm{ppmv})^{-1}\right]$ or between the ECP8.5 and PI simulations [ 9.0 $\left.0^{\circ} \mathrm{C}(1720 \mathrm{ppmv})^{-1}\right]$. This nonlinear relationship is due to other external
TABLE 2. Global-mean SAT $\left({ }^{\circ} \mathrm{C}\right)$ in the LGM, PI, ECP4.5, and ECP8.5 simulations. The MMM value and the intermodel standard deviation are also indicated in the bottom row.

\begin{tabular}{lrccc}
\hline \multicolumn{1}{c}{ Model } & LGM & PI & ECP4.5 & ECP8.5 \\
\hline CCSM4 & 8.4 & 13.3 & 16.5 & 22.3 \\
CNRM-CM5 & 10.6 & 13.2 & 16.2 & 22.9 \\
FGOALS-g2 & 7.7 & 12.3 & 14.4 & - \\
GISS-E2-R & 9.5 & 14.3 & 16.5 & 19.7 \\
IPSL-CM5A-LR & 7.4 & 12.1 & 15.9 & 24.0 \\
MIROC-ESM & 8.6 & 13.8 & 17.0 & - \\
MMM & $8.7 \pm 1.2$ & $13.2 \pm 0.8$ & $16.1 \pm 0.9$ & $22.2 \pm 1.8$ \\
\hline
\end{tabular}

forcings that are nonmonotonically prescribed in each simulation (e.g., stratospheric ozone and aerosols) and the complicated climate feedbacks taking place. Based on this fact, $\mathrm{HC}$ change from cold to warm climate is scaled using the SAT change instead of the $\mathrm{CO}_{2}$ concentration change (see next section). In other words, the dynamic (or circulation) sensitivity is related to the equilibrium climate sensitivity in this study (e.g., Lu et al. 2007; Grise and Polvani 2016).

Figures $1 \mathrm{a}-\mathrm{c}$ display the zonal-mean temperature difference of the LGM, ECP4.5, and ECP8.5 simulations against the PI simulations (see figure caption). Only the MMM fields are shown with the reference temperature profile from the PI simulations (contours). The zonalmean temperature in LGM condition is colder than in PI condition almost everywhere except in the stratosphere (Fig. 1a). The opposite is true for ECP4.5 condition (Fig. 1b). The spatial distribution of temperature difference is remarkably similar to that of LGM condition with an opposite sign (cf. Figs. 1a,b). Among others, Arctic amplification and enhanced tropical uppertropospheric temperature changes are robustly found in Figs. 1a,b. Figure 1c further demonstrates that temperature change in the increased warming scenario (ECP8.5) is essentially similar to that in the moderate warming scenario (ECP4.5) with a larger amplitude. A direct comparison between Figs. $1 \mathrm{~b}$ and 1c, however, should be done with caution, because the ECP8.5 MMM is derived from only four models (Table 1).

Figures $1 \mathrm{~d}-\mathrm{f}$ further illustrate mean meridional circulation $\psi$ changes. As in Figs. 1a-c, the MMM $\psi$ of PI simulations is contoured and its difference from other equilibrium states $\Delta \psi$ are shaded. To highlight tropical circulation changes, all variables are presented only from $60^{\circ} \mathrm{S}$ to $60^{\circ} \mathrm{N}$. Although circulation changes are observed not only in the tropics but also in the extratropics, only tropical circulation changes are discussed in this study. Extratropical circulations will be investigated in a future study.

It is evident from Fig. 1d that the LGM HC is somewhat stronger than the PI HC, especially in the $\mathrm{NH}$ 
(a) $\Delta \mathrm{T}[\mathrm{LGM}-\mathrm{PI}]$

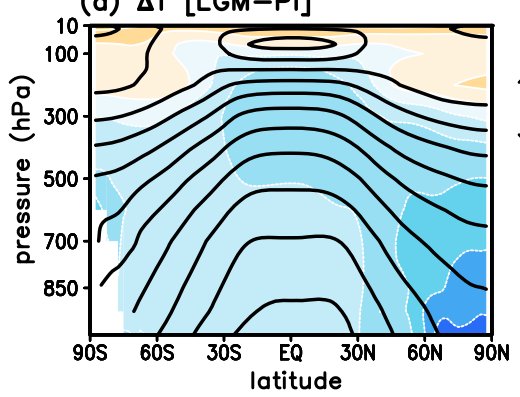

(d) $\Delta \Psi[L G M-P I]$

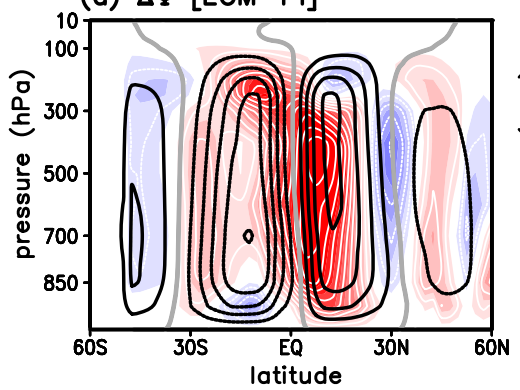

(b) $\Delta \mathrm{T}[\mathrm{ECP} 4.5-\mathrm{PI}]$

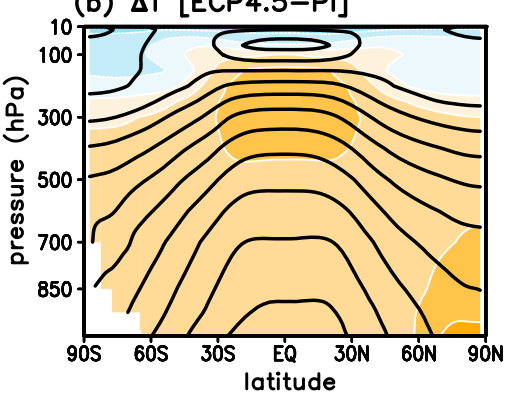

(e) $\Delta \Psi$ [ECP4.5-PI]

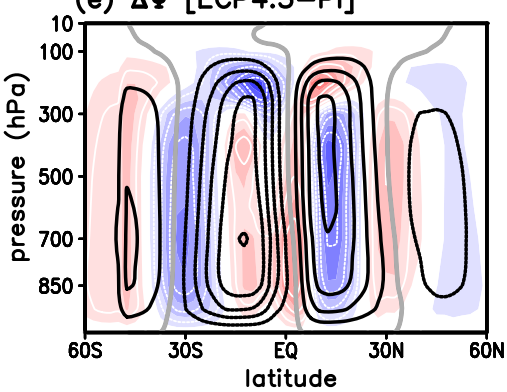

(c) $\triangle \mathrm{T}[\mathrm{ECP} 8.5-\mathrm{PI}]$
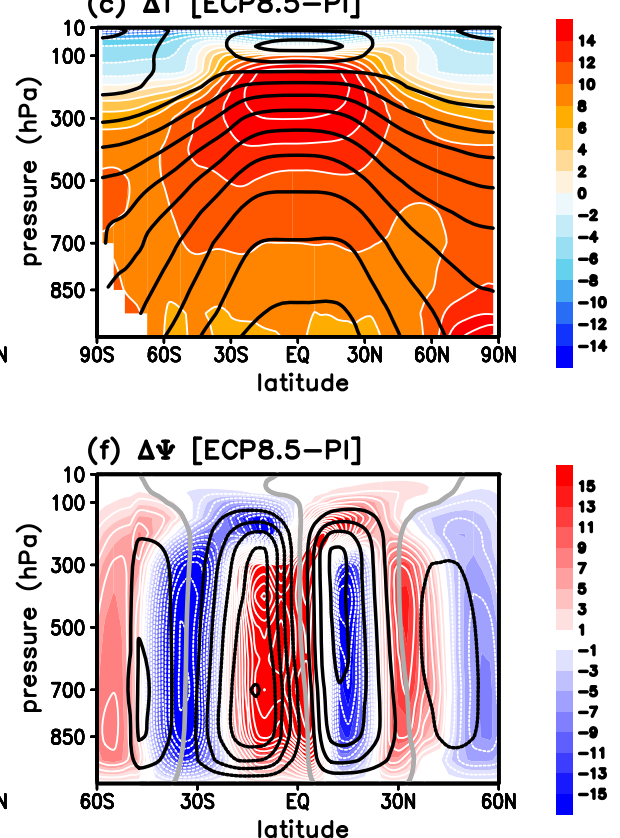

FIG. 1. Multimodel mean of (a)-(c) zonal-mean temperature (K) and (d)-(f) mass streamfunction $\left(10^{10} \mathrm{~kg} \mathrm{~s}^{-1}\right)$ differences of (a),(d) LGM, (b),(e) ECP4.5, and (c),(f) ECP8.5 simulations against the PI simulations. Contours indicate the MMM of the PI simulations. Note that the latitudinal range of (a)-(c) is different from that of (d)-(f).

(positive $\psi 500$ at $\sim 15^{\circ} \mathrm{N}$ ). Such a strengthening is not present in the $\mathrm{SH}$ (positive $\psi 500$ at $\sim 15^{\circ} \mathrm{S}$ ), indicating a hemispherically asymmetric HC-strength change. In the upper troposphere, a pair of a positive $\Delta \psi$ at approximately $10^{\circ} \mathrm{S}$ and a negative $\Delta \psi$ at approximately $15^{\circ} \mathrm{N}$ appears. This dipolar $\Delta \psi$ indicates a downward contraction of the $\mathrm{HC}$ in both hemispheres. In the subtropics, a positive $\Delta \psi$ at approximately $30^{\circ} \mathrm{S}$ and a negative $\Delta \psi$ at approximately $30^{\circ} \mathrm{N}$ are also evident. In terms of the zero-crossing latitude of $\psi 500$, these $\Delta \psi$ patterns suggest an equatorward shift of the $\mathrm{HC}$ edges in both hemispheres. In other words, the $\mathrm{HC}$ width in the LGM simulations is somewhat narrower than that in the PI simulations.

The opposite results are found in the ECP4.5 simulations (Fig. 1e). The NH HC in the ECP4.5 simulations is weaker than the one in the PI simulations (negative $\psi 500$ at $\sim 15^{\circ} \mathrm{N}$ ). A slight weakening is also observed in the $\mathrm{SH}$ (weak positive $\psi 500$ at $\sim 15^{\circ} \mathrm{S}$ ) as in LGM minus PI conditions, indicating nonmonotonic SH HCstrength change from the LGM to ECP4.5 simulations. In the tropical upper troposphere, a dipolar $\Delta \psi$ appears again but with an opposite sign to that in LGM minus PI conditions. This result indicates an upward expansion of the HC. In the subtropics, a negative $\Delta \psi$ at approximately $30^{\circ} \mathrm{S}$ and a weak but nonnegligible positive $\Delta \psi$ at approximately $30^{\circ} \mathrm{N}$ are further observed. These $\Delta \psi$ patterns are again opposite to those in LGM condition, indicating a wider $\mathrm{HC}$ in the ECP4.5 simulations than in the PI simulations. A qualitatively similar result, with a larger amplitude, is further found under the increased warming scenario (cf. Figs. 1e and 1f).

\section{Hadley cell}

The above results indicate that the $\mathrm{HC}$ tends to expand upward and poleward in both hemispheres under global warming. This hemispherically symmetric change, however, is not present in $\mathrm{HC}$ strength change. While the SH HC strength does not change much, the NH HC tends to weaken with global warming. These results are more quantitatively evaluated in this section. For statistical analysis, the Student's $t$ test is used.

\section{a. HC width}

Figure 2 presents the $\mathrm{HC}$ edge in each hemisphere and its total width. For comparison, besides the $\psi 500$ metric, the SLP metric is also used. The different climate states are denoted with different colors, and the individual models are indicated by different symbols. The reference value, derived from the three reanalysis datasets (denoted as REANA), is also indicated with an open diamond.

As speculated in section 2 , the $\psi 500$-based $\mathrm{HC}$ width is qualitatively similar to the SLP-based width (Fig. 2a). Their correlation across the different climate states is 

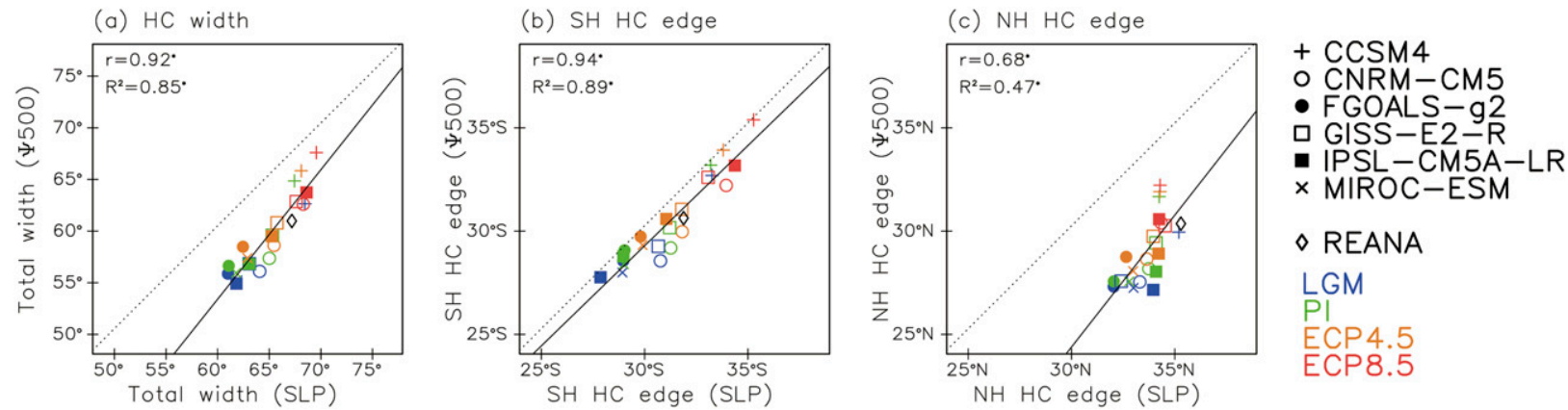

FIG. 2. (a) HC width and (b),(c) HC edges in the two hemispheres determined by the $\psi 500$ metric ( $y$ axis) and the SLP metric ( $x$ axis). Each model and each climate state are shown in different symbols and colors. The $r$ and the coefficient of determination $R^{2}$ that are statistically significant at the $95 \%$ confidence level are indicated with an asterisk. See the text for details on the $\psi 500$ and SLP metrics.

0.92 , and this is statistically significant at the $99 \%$ confidence level. This strong correlation is mainly due to their one-to-one correspondence in the SH (Fig. 2b). A strong linear relationship in the $\mathrm{SH}$ is observed in all seasons with a maximum correlation of 0.97 during the austral summer [December-February (DJF)] and a minimum correlation of 0.79 during the austral winter [June-August (JJA)]. Even in the NH, the two metrics are linearly correlated with each other, with a correlation coefficient $r$ of 0.68 (Fig. 2c). However, their link in the $\mathrm{NH}$ is rather weak in comparison to that in the $\mathrm{SH}$ and their ratio is close to $1: 1.3$ instead of $1: 1$. Although the factors that control the ratio of the $\psi 500$-based $\mathrm{HC}$ edge to the SLP-based $\mathrm{HC}$ edge remain to be determined, a rather weak relationship in the $\mathrm{NH}$ is readily anticipated because of the pronounced land-sea contrast and topography in the NH. The land-sea contrast introduces zonally asymmetric surface friction that is not taken into account in the SLP-based metric [note that linear friction is assumed in Eq. (2)]. Over the topography, SLP is also less reliable because of extrapolation. These do not guarantee a geostrophic balance at the sea level [Eq. (5)].

Figure $2 b$ further reveals that the SH HC edges in PMIP3 and CMIP5 simulations are significantly biased equatorward. Most simulations, except for all CCSM4 simulations and ECP8.5 simulations, show the SH HC edges located at the lower latitudes in comparison to the reanalysis data (open diamond). This equatorward bias is consistent with the equatorward bias of the SH westerly jet in both PMIP3 (Rojas 2013) and CMIP5 simulations (Wilcox et al. 2012; Barnes and Polvani 2013; Gerber and Son 2014). A similar bias has been also reported in the PMIP2 (Rojas 2013), CMIP3 (Kidston and Gerber 2010), and chemistry-climate model simulations (Son et al. 2010), suggesting that current-generation climate models fail to reproduce the $\mathrm{SH}$ zonal-mean circulation.
An equatorward bias is also evident in the $\mathrm{NH}$ (Fig. 2c). All simulations (i.e., six models for all scenarios) show such a bias. A similar bias is further found in the CMIP5 historical simulations (Davis and Birner 2017). Consistent with this bias, the Atlantic jet is significantly biased equatorward in both historical and scenario simulations (Barnes and Polvani 2013).

In spite of the model mean biases, the $\mathrm{HC}$ width systematically changes from cold (blue) to warm climate (orange and red in Fig. 2a). In LGM simulations, the HC widths, defined by the $\psi 500$ metric ( $y$ axis), are clustered around the $56.8^{\circ}$ latitude. Those in PI and ECP4.5 simulations are clustered around the $58.4^{\circ}$ and $60.0^{\circ}$ latitudes, respectively. This indicates a widening of the HC from the LGM to the ECP4.5 simulations. As hinted in Figs. 2b,c, such a change is observed in both hemispheres. Climatological SH HC edges in LGM, PI, and ECP4.5 simulations are $29.1^{\circ} \mathrm{S} \pm 1.8^{\circ}$ lat, $29.8^{\circ} \mathrm{S} \pm 1.8^{\circ}$ lat, and $30.7^{\circ} \mathrm{S} \pm 1.7^{\circ}$ lat, respectively. Likewise, $\mathrm{NH} \mathrm{HC}$ edges in these three climate states are $27.7^{\circ} \mathrm{N} \pm 1.1^{\circ}$ lat, $28.7^{\circ} \mathrm{N} \pm 1.6^{\circ}$ lat, and $29.3^{\circ} \mathrm{S} \pm 1.4^{\circ}$ lat, respectively.

A qualitatively similar result is also found using the SLP metric ( $x$ axis in Figs. 2a-c). However, the longterm change in this metric is less clear compared to that of the $\psi 500$ metric. For example, CCMS4, FGOALS-g2, and MIROC-ESM essentially show no change in HC width from the LGM to the ECP4.5 simulations (Fig. 2a). This is particularly true in the NH, where most models show nonsystematic HC-width changes (Fig. 2c). This result clearly suggests that not only the model mean bias but also its long-term change are sensitive to the definition used (e.g., Davis and Rosenlof 2012; Lucas et al. 2014). With this uncertainty in hand, the discussion below is focused on the $\psi 500$-based HC. Here the $\psi 500$ metric is selected not because it is more reliable than the SLP metric but because it allows for an easy comparison with the previous studies, which typically used the $\psi 500$ metric. 
(a) HC width

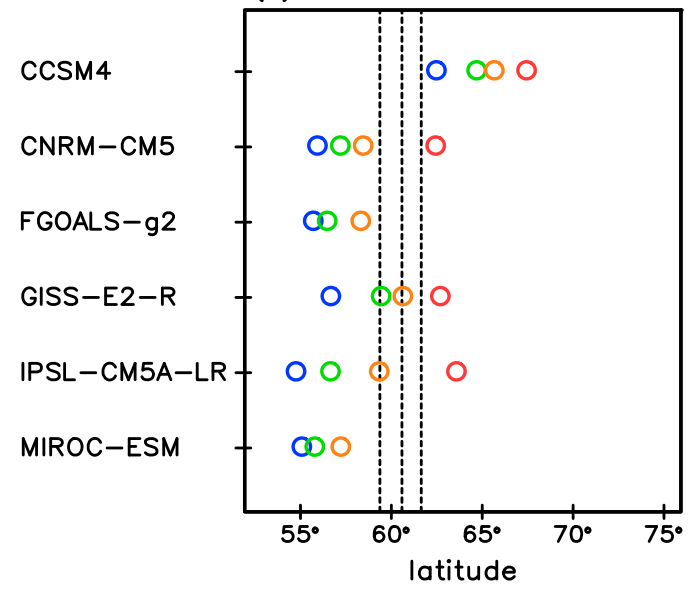

(b) $\mathrm{SH}$ edge

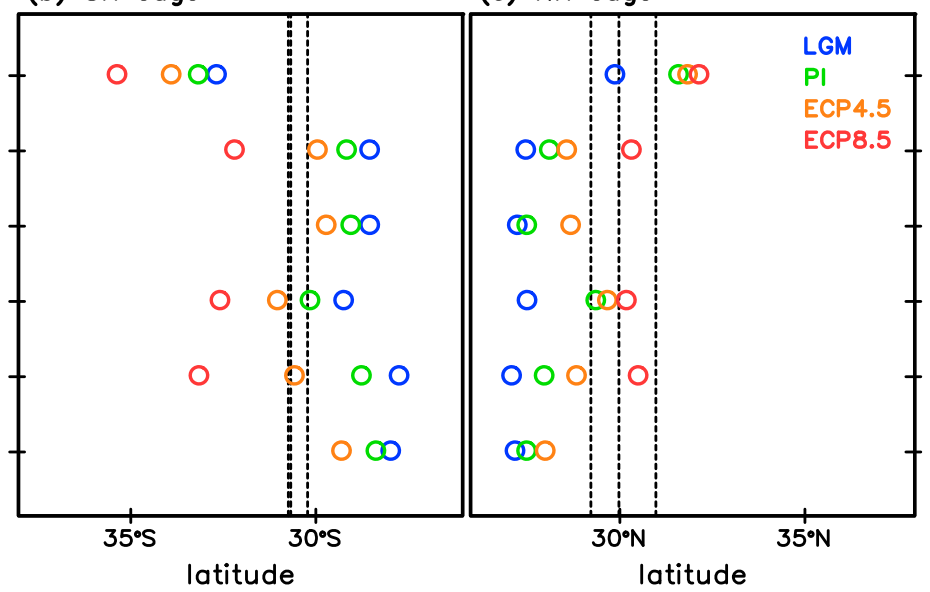

FIG. 3. (a) HC width, (b) SH edge, and (c) NH edge, determined by the $\psi 500$ metric, for each climate state for each model. Dotted lines denote the climatological $\mathrm{HC}$ width and edges estimated from the three reanalysis datasets.

The $\mathrm{HC}$ widening in each model is more explicitly illustrated in Fig. 3a. Most models show a systematic widening of the HC from the LGM to the PI, and to the ECP4.5 and ECP8.5 simulations. Such a widening is robustly found in both hemispheres (Figs. 3b,c). It is also evident from Fig. 3 that the intermodel spread of the $\mathrm{HC}$ widening is substantially large. This is particularly true if compared with uncertainty of reanalysis datasets (dashed lines). While GISS-E2-R and IPSL-CM5A-LR exhibit about $4^{\circ}$ latitude or even larger $\mathrm{HC}$ widening from the LGM to the ECP4.5 conditions, others show only $2^{\circ}-3^{\circ}$ latitude widening. It is unclear what controls this difference. Kidston and Gerber (2010) and Son et al. (2010) highlighted that zonal-mean circulation changes to a given forcing are sensitive to model mean biases. Davis and Birner (2017) further suggested that intermodel spread in $\mathrm{HC}$ widening is partly dependent on model resolution. However, with the limited sample size used in this study (only six models), these conjectures are difficult to evaluate. Further studies using more models are necessary to identify the factors that control quantitatively different circulation changes to the same external forcing.

Looking at Fig. 3, it is natural to inquire whether the $\mathrm{HC}$ width linearly changes in response to the SAT change. To address this issue, the relationship between $\mathrm{HC}$-width and SAT changes is investigated in Figs. $4 \mathrm{a}-\mathrm{c}$. The relative changes, with respect to PI condition, are shown here to eliminate model mean bias. It is clear that all LGM simulations show a relatively narrower HC than PI simulations do (bottom-left corner in Fig. 4a). In contrast, all ECP4.5 and ECP8.5 simulations show a wider HC (top-right corner). More importantly, these HC-width changes are linearly associated with the SAT changes. Their correlation coefficient is 0.95 , and this is statistically significant at the $99 \%$ confidence level.

A strong linear relationship is observed not only in the $\mathrm{SH}$ (Fig. 4b) but also in the NH (Fig. 4c), indicating that the $\mathrm{HC}$ edges in both hemispheres shift poleward with an increasing SAT. However, their seasonality is somewhat different in the two hemispheres. As summarized in Table 3, the SH HC widening is statistically significant in all seasons. However, the $\mathrm{NH}$ HC edge shows a slight equatorward shift during the boreal summer (JJA) in contrast to the other seasons. This abnormal trend in JJA, which is also found in quadrupling $\mathrm{CO}_{2}$ experiments (Grise and Polvani 2016), is likely caused by the fact that $\mathrm{NH}$-summer $\mathrm{HC}$ is weak and often not well defined (see Table 4).

Table 3 summarizes that the annual-mean $\mathrm{HC}$ widening is in a rate of about $4.5^{\circ}$ latitude per $10^{\circ} \mathrm{C}$ warming. This widening, which is stronger in the $\mathrm{SH}$ than in the $\mathrm{NH}$, is quantitatively similar to the MMM HC widening in the idealized model experiments $\left(4^{\circ}-4.5^{\circ}\right.$ latitude widening per $10^{\circ} \mathrm{C}$ warming; Frierson et al. 2007), in the CMIP3 SRES A2 scenario simulations (approximately $6^{\circ}$ latitude widening per $10^{\circ} \mathrm{C}$ warming; Lu et al. 2007), and in the CMIP5 representative concentration pathway 8.5 (RCP8.5) scenario simulations (approximately $5^{\circ}$ latitude widening per $10^{\circ} \mathrm{C}$ warming; Vallis et al. 2015). This trend, however, is much weaker than the historical trend over the period of 1980-2010 in the three reanalysis datasets $\left(9^{\circ}-24^{\circ}\right.$ latitude widening per $10^{\circ} \mathrm{C}$ warming $)$. The discrepancy (and large uncertainty in the reanalysis datasets) is likely caused by the internal variability (Allen et al. 2014; Garfinkel et al. 2015; Mantsis et al. 2017).

What drives $\mathrm{HC}$ widening? Without controlled model experiments, it is difficult to address this question. A 
(a) HC width

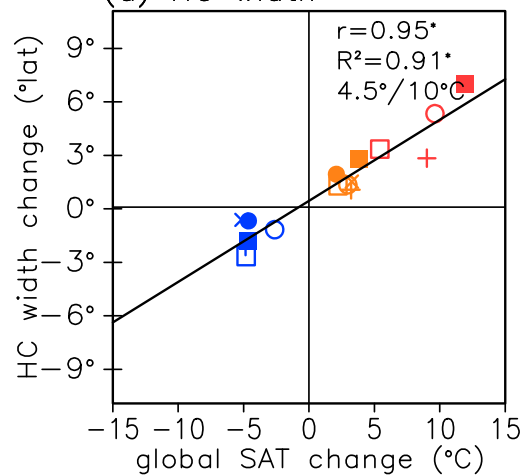

$+\operatorname{CCSM} 4$

O CNRM-CM5

- FGOALS-g2

GISS-E2-R

- IPSL-CM5A-LR

$\times$ MIROC-ESM

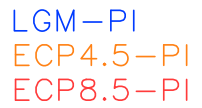

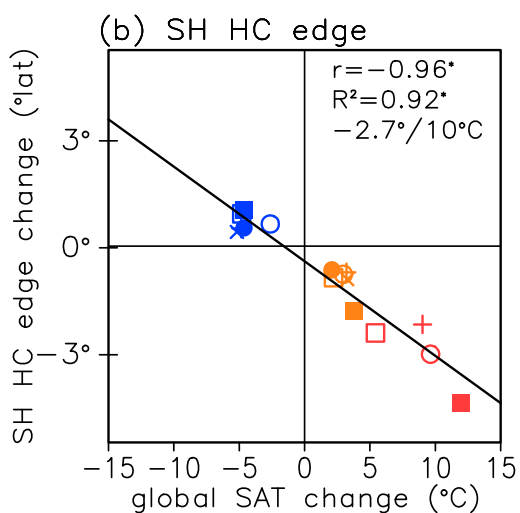
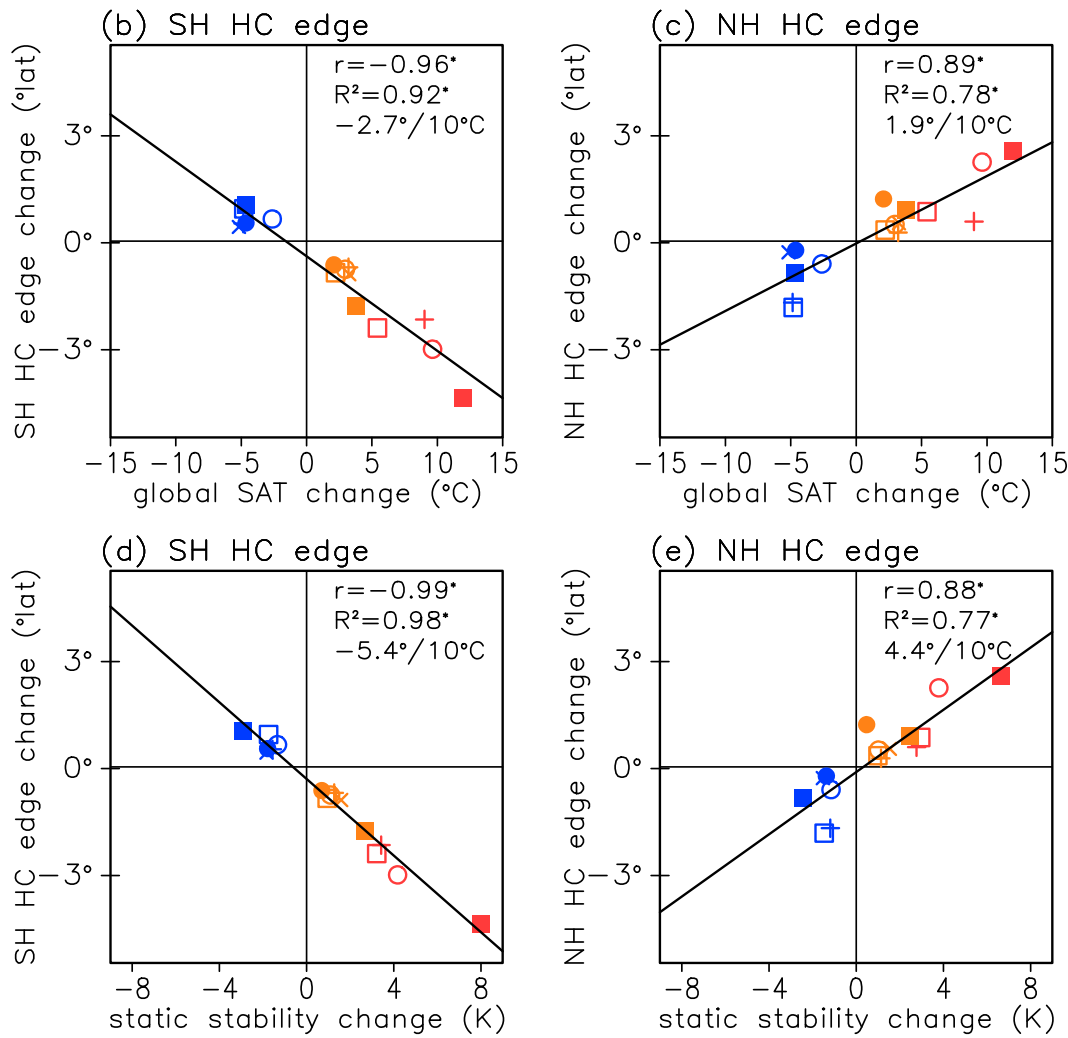

(f) $\mathrm{SH} \mathrm{HC}$ edge

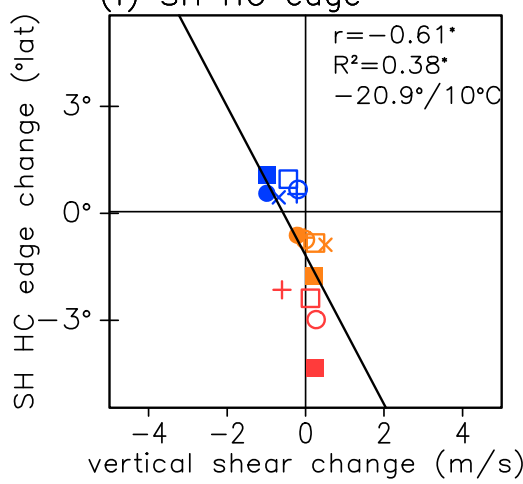

FIG. 4. (a)-(c) HC-width and HC-edge changes ( $y$ axis) in response to the global SAT changes ( $x$ axis). The difference from the PI simulations is shown in a different color. (d)-(g) HC-edge change with respect to (d),(e) static stability change and (f),(g) vertical shear change. The $r$ and $R^{2}$ that are statistically significant at the $95 \%$ confidence level are indicated with an asterisk.

first-order explanation, however, can be offered by use of a simple scaling analysis. In the absence of eddies, the axisymmetric $\mathrm{HC}$ is controlled by the equator-pole temperature difference and the tropopause height (Held and Hou 1980), with a possible contribution of the gross static stability (Schneider 1977). However, in the atmosphere, baroclinic eddies effectively modify the HC width and strength (e.g., Kim and Lee 2001; Walker and Schneider 2006), and it has been proposed that the poleward edge of the $\mathrm{HC}$ is primarily set by the latitude where baroclinic instability becomes significantly strong [Held 2001; see also recent review by Vallis et al. (2015)]. Since linear baroclinicity is a function of dry static stability and vertical wind shear, a wider HC (or poleward shift of the $\mathrm{HC}$ edge) is expected with increasing subtropical static stability and decreasing vertical wind shear that may reduce the baroclinic eddy activity in the subtropics and shift the baroclinic zone poleward. Although this argument does not reveal a causal relationship, it still provides a helpful insight. 
TABLE 3. $\mathrm{HC}$-width and $\mathrm{HC}$-edge changes per $10^{\circ} \mathrm{C}$ warming of the global-mean SAT $\left[{ }^{\circ}\right.$ lat $\left(10^{\circ} \mathrm{C}\right)^{-1}$ ]. All available simulations are used for the annual-mean and seasonal-mean relationships. Note that negative values in the $\mathrm{SH}$ but positive values in the $\mathrm{NH}$ denote a poleward shift of the $\mathrm{HC}$ edge. The reference values, derived from the PI simulations, are also indicated in parentheses ( ${ }^{\circ}$ lat). The values that are statistically significant at the $95 \%$ confidence level are denoted with an asterisk.

\begin{tabular}{lccc}
\hline & Total HC width & SH HC edge & NH HC edge \\
\hline Annual & $4.5^{*}(58.4)$ & $-2.7^{*}(-29.8)$ & $1.9^{*}(28.7)$ \\
MAM & $6.5^{*}(55.6)$ & $-4.5^{*}(-30.4)$ & $2.0^{*}(25.2)$ \\
JJA & $0.1(58.5)$ & $-2.5^{*}(-27.4)$ & $-2.4(31.1)$ \\
SON & $5.7^{*}(60.9)$ & $-1.9^{*}(-29.0)$ & $3.8^{*}(31.9)$ \\
DJF & $4.9^{*}(61.5)$ & $-2.6^{*}(-33.9)$ & $2.4^{*}(27.6)$ \\
\hline
\end{tabular}

As shown in Figs. 1a-c, temperature differences in each simulation, against the PI simulations, are not homogeneous in space. Because of moist adiabatic adjustment and other climate feedbacks, temperature changes in the tropical upper troposphere are typically stronger than those in the lower troposphere. The latitudinal temperature distribution also varies from one climate state to the other. These can effectively change the linear baroclinicity in the subtropics. In this study, baroclinicity is quantified by the Phillips supercriticality C (Phillips 1954):

$$
C \equiv \frac{f^{2}\left(u_{500}-u_{850}\right)}{\beta g H\left(\theta_{500}-\theta_{850}\right) / \Theta_{0}},
$$

where $u$ and $\theta$ are the long-term mean zonal wind and potential temperature, respectively. Following $\mathrm{Lu}$ et al. (2008), both the vertical wind shear $u_{500}-u_{850}$ and the dry static stability $\theta_{500}-\theta_{850}$ are calculated with zonalmean fields at 500 and $850 \mathrm{hPa}$. They are then averaged in the subtropics, over $\pm 10^{\circ}$ latitude about the $\mathrm{HC}$ edge, in each hemisphere. Although not shown, the fixed latitude (i.e., $20^{\circ}-40^{\circ} \mathrm{N}$ and $20^{\circ}-40^{\circ} \mathrm{S}$ ) for all model simulations shows essentially the same result. Other variables are set to a constant (i.e., thickness or tropopause height $H$, reference potential temperature $\Theta_{0}$, and gravity $g$ ). Likewise, the Coriolis parameter $f$ and its latitudinal gradient $\beta$ are constant. Note that tropopause height is not fixed but changes across different climate states (Lu et al. 2007; Son et al. 2009a). However, its change is not considered here because it is inherently related with static stability change.

Figures $4 \mathrm{~d}-\mathrm{g}$ illustrate the relationship between HCedge change and baroclinicity change. The relative importance of static stability versus vertical wind shear changes is particularly examined. It is clear that HCedge changes in both hemispheres are highly correlated with static stability changes (Figs. 4d,e) with a weak
TABLE 4. As in Table 3, but for the percentage change of the HC strength per $10^{\circ} \mathrm{C}$ warming. The percentage change is calculated with respect to the PI simulations (denoted in parentheses; $\left.10^{10} \mathrm{~kg} \mathrm{~s}^{-1}\right)$.

\begin{tabular}{lcrr}
\hline \hline & Total HC strength & SH strength & NH strength \\
\hline Annual & $-10.5^{*}(14.4)$ & $-2.8(7.6)$ & $-19.0^{*}(6.9)$ \\
MAM & $-7.9^{*}(11.3)$ & $-10.5^{*}(7.5)$ & $-1.3(3.8)$ \\
JJA & $-10.3^{*}(10.3)$ & $3.6(7.8)$ & $-58.3^{*}(2.6)$ \\
SON & $-7.9^{*}(13.2)$ & $12.9(5.3)$ & $-21.8^{*}(7.8)$ \\
DJF & $-16.2^{*}(13.4)$ & $-23.4^{*}(5.0)$ & $-11.1(8.4)$ \\
\hline
\end{tabular}

relationship with vertical wind shear changes (Figs. 4f,g). The high correlations (i.e., -0.99 in the $\mathrm{SH}$ and 0.88 in the $\mathrm{NH}$ ) are somewhat anticipated from the linear relationship between HC-edge change and SAT change (Figs. $4 a-c)$. As noted above, global warming typically accompanies an enhanced thermal stratification in low latitudes. This result, which is consistent with previous studies (Held 2001; Lu et al. 2007; Vallis et al. 2015), suggests that the $\mathrm{HC}$ widening from the LGM to ECP4.5 simulations is likely caused by an enhanced subtropical static stability in response to global warming. An enhanced subtropical static stability results in a poleward shift of baroclinic eddy activities, possibly causing Rossby wave breaking (and eddy momentum flux) in a higher latitude. Although not shown, HC-edge change is also closely related with tropical upper-tropospheric temperature change and the related meridional temperature gradient change, as anticipated from the spatial structure of temperature difference in Figs. 1a-c.

\section{b. HC strength}

As suggested in Figs. 1d-f and discussed in section 3, not only $\mathrm{HC}$ width but also $\mathrm{HC}$ strength varies from cold to warm climate. Specifically, the HC strength gets weaker from the LGM to the ECP4.5 conditions in the $\mathrm{NH}$, although such changes are not evident in the SH.

Figure 5 presents the relationship between the HC strength and width among all available simulations. As described in section 2, HC strength is simply defined by the maximum value of $|\psi 500|$ within the $\mathrm{HC}$ in each hemisphere (Figs. 5b,c). Following Lu et al. (2007), their sum, referred to as total strength, is also presented in Fig. 5a. Unlike the HC width, HC strength does not show any systematic change from the LGM to the ECP4.5 simulations (Fig. 5a). While some models show a noticeable negative correlation between HC width and strength changes (e.g., CCSM4 and CNRMCM5), others show no clear relationship. In comparison to the $\mathrm{SH}$, the $\mathrm{NH} \mathrm{HC}$ strength is more linearly correlated with its width (cf. Figs. 5b,c). Most models, except for GISS-E2-R, exhibit a poleward shift and a weakening 

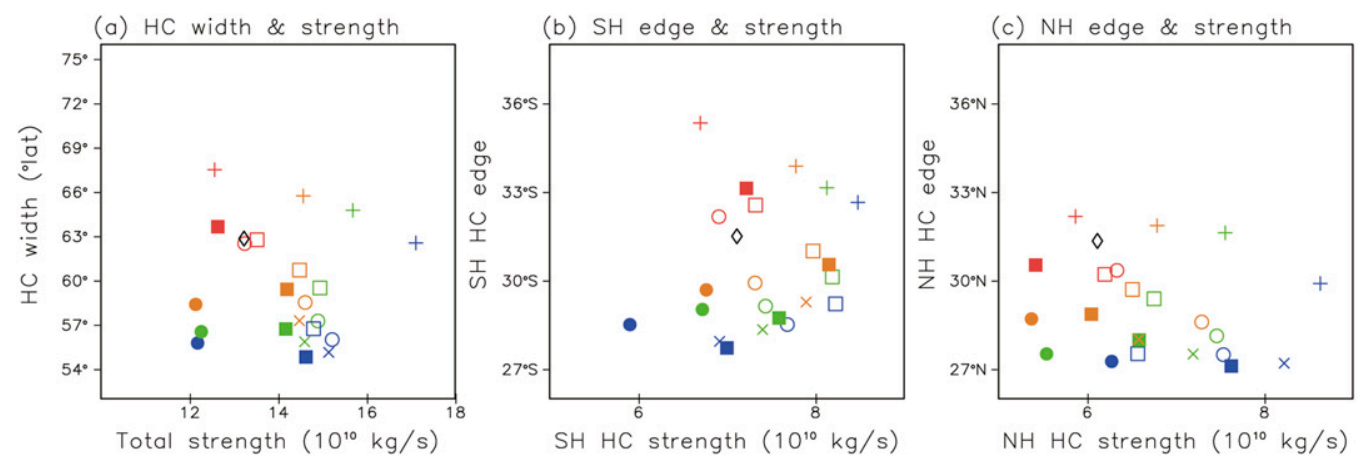

$+\operatorname{CCSM} 4$

O CNRM-CM5

- FGOALS-g2

GISS-E2-R

- IPSL-CM5A-LR

$\times$ MIROC-ESM

$\diamond$ REANA

LGM

$\mathrm{PI}$

ECP 4.5

ECP8.5

FIG. 5. The relationship between (a) total HC width and total HC strength among different climate states. (b), (c) As in (a), but for the HC edge and strength in each hemisphere.

of the NH HC from the LGM to ECP4.5 or ECP 8.5 simulations.

The nonsystematic relationship, shown in Fig. 5, is not surprising. As discussed in section 2, the HC edge is primarily set by the latitudinal location of the maximum or the minimum eddy momentum flux in the upper troposphere. Its strength, however, is determined by the maximum eddy momentum flux divergence [Eq. (3)] and angular-momentum-conserving flow. This distinction implies that $\mathrm{HC}$-width change does not necessarily accompany HC-strength change. A consistent widening and weakening of the $\mathrm{HC}$ could only occur when the latitude of the maximum eddy momentum flux shifts poleward with a reduced intensity (if angularmomentum-conserving flow is ignored). If its intensity is increased, an $\mathrm{HC}$ widening could be accompanied by HC strengthening instead of weakening. This may explain the varying $\mathrm{HC}$ width-strength relationship among the models. To evaluate this argument, daily momentum fluxes need to be analyzed. However, such datasets are not available in most models.
Figure 6 presents the HC strength in each model simulation as in Fig. 3. In comparison to the reanalysis datasets (dashed lines), total strength is somewhat underestimated (Fig. 6a). A clear outlier is the FGOALSg2, which substantially underestimates HC strength in both hemispheres (Figs. 6b,c). All three simulations show the HC strength much weaker than that in the reanalysis data. In terms of long-term change, a slight $\mathrm{HC}$ weakening is observed in Fig. 6a. Quantitatively, total HC strengths in the LGM, PI, and ECP4.5 simulations are $14.8 \pm 1.6,14.4 \pm 1.2$, and $14.1 \pm 1.0 \times$ $10^{10} \mathrm{~kg} \mathrm{~s}^{-1}$, respectively (Fig. 6a). This weakening, which is consistent with Lu et al. (2007), is primarily due to the NH HC weakening (Fig. 6c). All models, except for GISS-E2-R, show a systematic weakening of the $\mathrm{NH}$ $\mathrm{HC}$. Such a change, however, does not appear in the $\mathrm{SH}$ (Fig. 6b). The SH HC strength instead exhibits a mixed response; that is, some models show a weakening (e.g., CCSM4), whereas other models show a strengthening (e.g., MIROC-ESM) or a nonlinear response (e.g., IPSL-CM5A-LR). As a result, the SH HC strengths in (a) Total strength

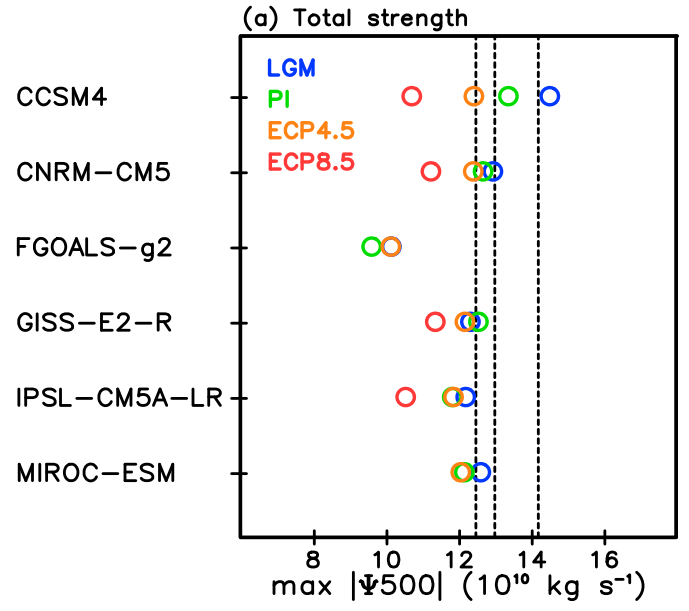

(b) $\mathrm{SH} \mathrm{HC}$ strength

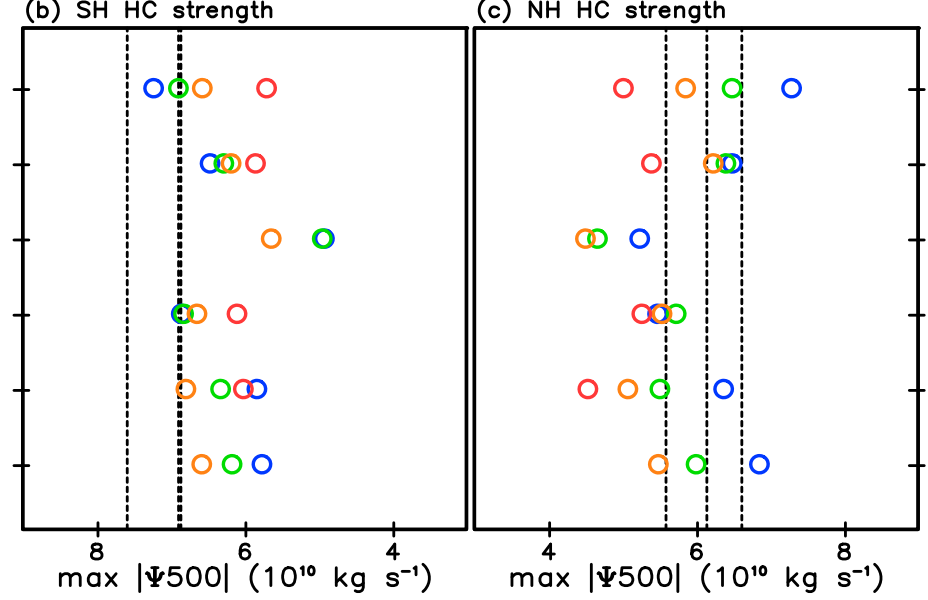

FIG. 6. (a) Total, (b) SH, and (c) NH HC strength for each climate state for each model. Overall format is identical to that of Fig. 3. 
(a) Total strength

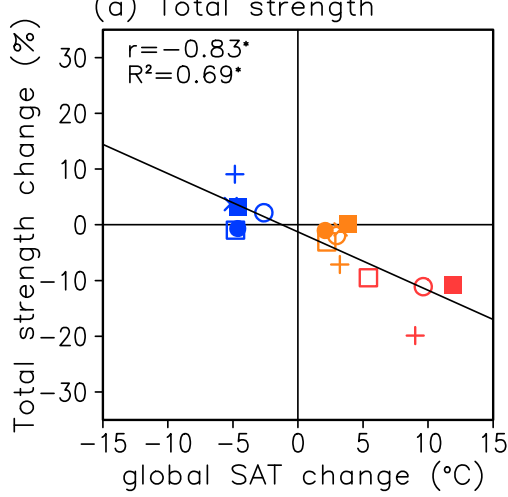

$+\operatorname{CCSM} 4$

O CNRM-CM5

- FGOALS-g2

$\square$ GISS-E2-R

- IPSL-CM5A-LR

$\times$ MIROC-ESM

LGM-PI

ECP 4.5-PI

ECP 8.5-PI (b) $\mathrm{SH} H C$ strength

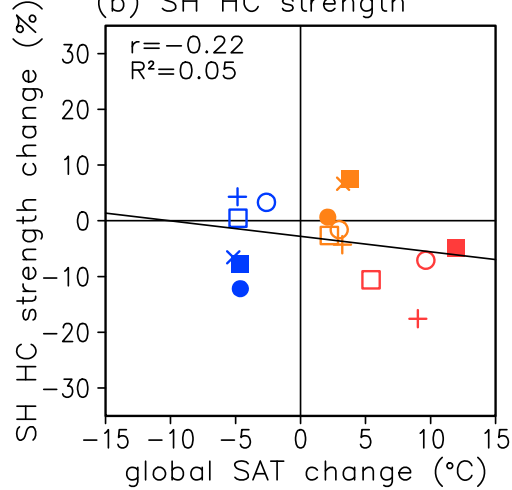

(d) $\mathrm{SH} H C$ strength

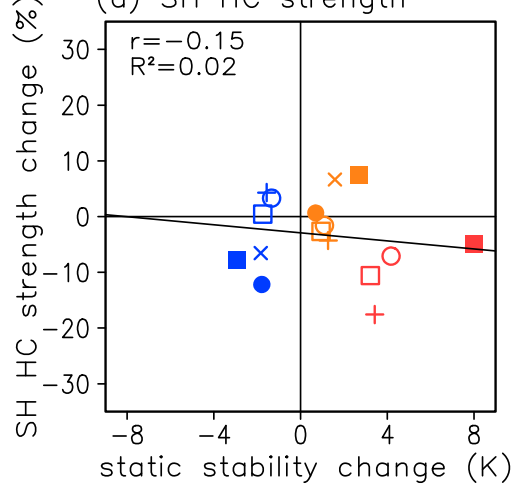

static stability change $(K)$

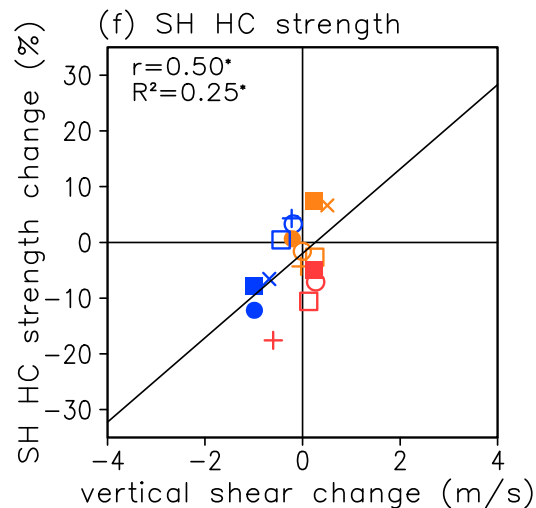

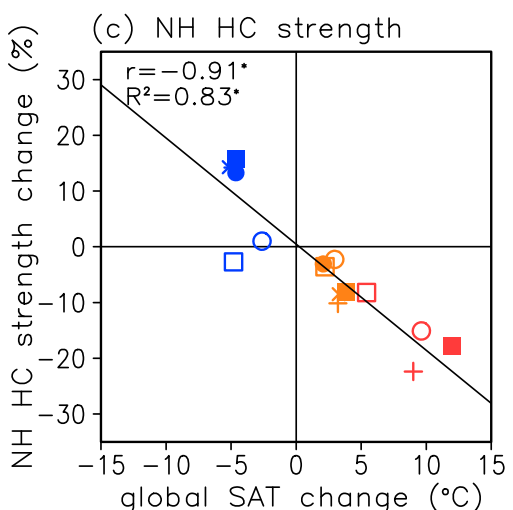
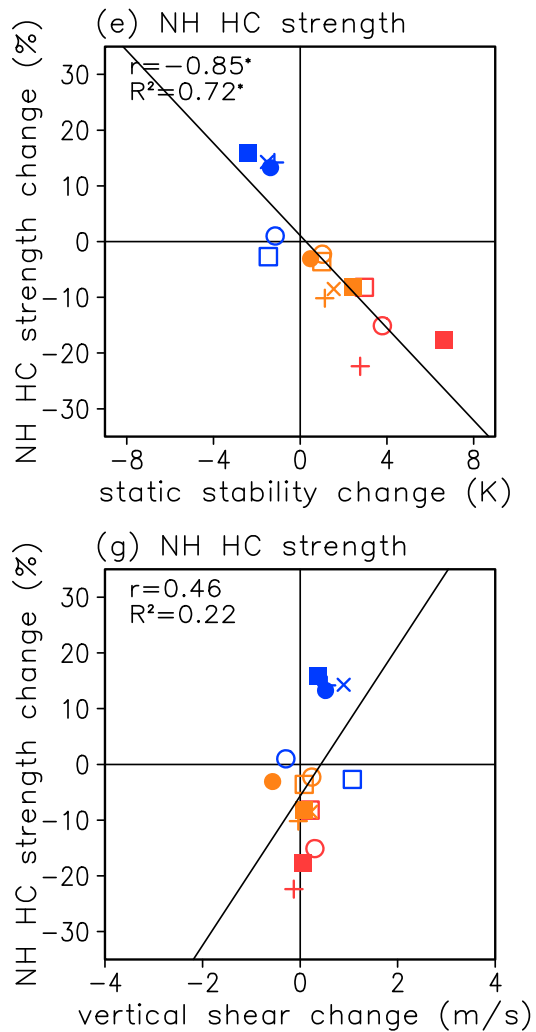

FIG. 7. Percentage changes of (a) total, (b) SH, and (c) NH HC strength against the global SAT changes. (d)-(g) HC-strength changes in each hemisphere against static stability and vertical shear changes. Overall format is identical to that of Fig. 4.

each climate state are almost indistinguishable. This hemispheric asymmetry in HC strength change is consistent with previous studies that documented a weakening of the $\mathrm{NH}$-winter $\mathrm{HC}$ but no change of the $\mathrm{SH}$-winter HC in the CMIP5 RCP8.5 simulations (Seo et al. 2014; Vallis et al. 2015).

Figure 7 further illustrates the relationship between HC-strength change and SAT change. To remove model mean bias, the percentage change with respect to the PI simulations is shown. A statistically significant relationship is observed in total strength change (Fig. 7a) with an approximately $10.5 \%$ weakening of the $\mathrm{HC}$ for a $10^{\circ} \mathrm{C}$ warming (Table 4). This change is quantitatively similar to the value estimated from the CMIP3 A2 scenario runs (about $12 \%$ weakening per $10^{\circ} \mathrm{C}$ warming; $\mathrm{Lu}$ et al. 2007). As noted above, the $\mathrm{HC}$ weakening is mainly due to the $\mathrm{NH} \mathrm{HC}$, which shows an approximately $19 \%$ weakening per $10^{\circ} \mathrm{C}$ warming (Fig. $7 \mathrm{c}$ ). In the $\mathrm{SH}, \mathrm{HC}$ strength does not change systematically (Fig. 7b) because of the cancellation between significant weakening in the austral summer (DJF) and fall [March-May (MAM)] and strengthening in the spring [September-November (SON)] (Table 4). Here it should be noted that the same percentage change in 

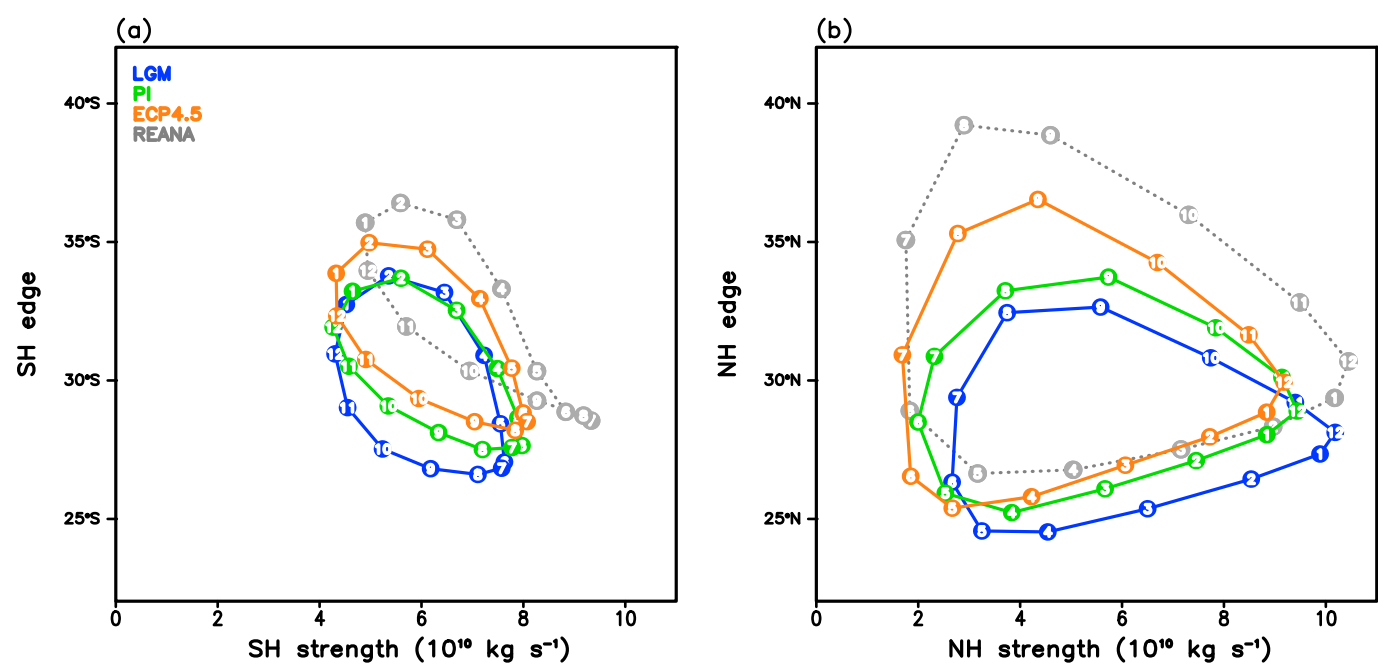

FIG. 8. Annual cycle of the MMM HC edge and strength in (a) SH and (b) NH. Each month is denoted with a number, and each climate state is indicated with different colors.

different seasons has different physical meanings. For example, a $11.1 \%$ change of NH HC strength in DJF is larger than a $58.3 \%$ change of JJA change because the DJF HC is much stronger than the JJA HC (see the numbers in parentheses in Table 4).

Figures $7 \mathrm{e}, \mathrm{g}$ indicate that the $\mathrm{NH} \mathrm{HC}$ weakening is closely related with static stability change $(r=0.85)$ rather than with the vertical wind shear change $(r=$ 0.46). Although not shown, similar results are found in all seasons. This result is in contrast to Seo et al. (2014), who reported a strong linear relationship between the $\mathrm{NH}$-winter HC strength and the vertical wind shear changes in CMIP5 RCP8.5 simulations.

\section{Summary and conclusions}

The atmospheric general circulation and its change in warm climate have been extensively examined in the last decade. Its structure in paleoclimate, however, has rarely been studied, partly because of insufficient observations and a limited number of climate model simulations. Inspired by Chavaillaz et al. (2013), the present study analyzes the Hadley cell (HC) and its long-term change not only in the present and warm climate but also in the paleoclimate. Both $\mathrm{HC}$ width and strength under the Last Glacial Maximum (LGM), preindustrial (PI), and extended concentration pathways 4.5 and 8.5 (ECP4.5 and ECP8.5) conditions are quantitatively evaluated by analyzing six models available from the PMIP3 and CMIP5 archives.

It is found that both the NH and SH HC edges systematically shift poleward with an increasing globalmean surface air temperature (SAT). This trend, which is stronger in the $\mathrm{SH}$ than in the $\mathrm{NH}$, is statistically significant in all seasons except for the boreal summer. For unknown reasons, the $\mathrm{NH}$-summer $\mathrm{HC}$ shows a slight equatorward shift from the LGM to the ECP4.5 conditions. In terms of the zero-crossing latitude of $500-\mathrm{hPa}$ streamfunction $\psi 500$, the annual-mean $\mathrm{HC}$ width (i.e., the latitudinal distance from the SH to NH HC edges) increases at a rate of about $4.5^{\circ}$ latitude widening per $10^{\circ} \mathrm{C}$ warming (Table 3 ). The HC strength, measured by the maximum value of $|\psi 500|$ within $\mathrm{HC}$, also shows a systematic change. Quantitatively, the total $\mathrm{HC}$ strength (i.e., the sum of the $\mathrm{SH}$ and $\mathrm{NH} \mathrm{HC}$ strength) gets weaker in a rate of about $10.5 \%$ weakening, with respect to PI condition, per $10^{\circ} \mathrm{C}$ warming (Table 4). Unlike HC widening, a statistically significant $\mathrm{HC}$ weakening is observed only in the NH. The SH HC does not show a systematic change because of the cancellation between its strengthening during the austral spring and its weakening during the austral summer-fall. This hemispheric asymmetry warrants further analyses.

Overall findings are summarized in Fig. 8, in terms of the annual cycle of the $\mathrm{HC}$ edge and its strength in each hemisphere (Nguyen et al. 2013). Only the multimodel mean (MMM) values, subject to 3-month running average, are presented for the LGM, PI, and ECP4.5 simulations. As a reference, $\mathrm{HC}$ properties derived from three reanalysis datasets are also shown in gray. In the SH (Fig. 8a), the HC edge is biased equatorward in most simulations (i.e., the colored dots are located at lower latitudes than the gray dots). This bias is relatively smaller in the ECP4.5 simulations than in the LGM simulations, indicating a poleward shift of the SH HC edge from the LGM to the ECP4.5 conditions. An 
equatorward bias is also evident in the NH (Fig. 8b). The NH HC edge also shows a relatively weaker seasonal cycle than the reanalysis data (i.e., the large circles connecting colored dots are smaller in size than the large gray circle in Fig. 8b). Most importantly, the NH HC exhibits not only a poleward expansion but also a weakening from the LGM to the PI and to the ECP4.5 simulations.

It should be noted that the values reported in this study should be considered with caution because only six models are analyzed. Multimodel analyses with such a small number of models can be easily biased by one or two outliers. To reduce such uncertainty, more models, which might be available in the next phase of PMIP and CMIP, should be considered. In addition, zonal-mean eddy fluxes, which are not available in most PMIP models, should be taken into account to better understand $\mathrm{HC}$ properties and their long-term changes.

It should be also emphasized that the $\psi 500$ metric is not the only available method to define the HC. Many different metrics have been used to determine the HC edge and the tropical width. They include maximum SLP, sharp gradient of tropopause height, frequency of double tropopauses, location of subtropical jet, cloud distribution, and precipitation minus evaporation, among others (Seidel et al. 2008; Davis and Rosenlof 2012; Lucas et al. 2014; Davis and Birner 2017). To better quantify the $\mathrm{HC}$ edge/width change and its uncertainty, a multi-index approach, using all or some of these metrics, may be useful (e.g., Solomon et al. 2016). As an example, the $\psi 500$ metric is compared with the SLP metric in this study. While quantitatively similar results are obtained in the $\mathrm{SH}$, significant differences are found in the NH. This definition-dependent $\mathrm{HC}$ width (or tropical width) change warrants further analyses.

Likewise, it is also questionable whether maximum $|\psi 500|$ is the optimal definition of $\mathrm{HC}$ strength. For instance, the 500-hPa level may not be the optimal level for $\mathrm{HC}$ detection. Even in the reanalysis datasets, the vertical structure of $|\psi 500|$ varies substantially. Some data show a vertically extended $\mathrm{HC}$, whereas others show the maximum $|\psi 500|$ either in the upper troposphere or in the lower troposphere (e.g., Stachnik and Schumacher 2011). This introduces a substantial uncertainty of the HC strength (see Fig. 6 for a large spread among the reanalysis datasets). As the vertical structure of the $\mathrm{HC}$ would change in time (e.g., upward expansion of the HC from the LGM to the ECP4.5 conditions), a fixed level for all model simulations in different climate states may not be ideal.

This study only explored tropical circulation. However, it is well known that tropical circulation is significantly modulated by extratropical circulation. Without a quantitative understanding of the extratropical circulation, such as westerly jets and storm tracks, a quantitative understanding of the $\mathrm{HC}$ in different climate states would not be possible. As such, further analyses on the extratropical circulation and its interaction with the tropical circulation are needed. The possible impact of stratospheric ozone also deserves further analyses. Although $\mathrm{HC}$ changes are primarily related with greenhouse gas-induced tropospheric warming in this study, they might be also influenced by different ozone concentration in each climate state. For instance, the nonsystematic SH HC-edge changes from the LGM to the ECP4.5 simulations during the late austral summer and early fall (Fig. 8a) could be associated with stratospheric ozone changes.

Acknowledgments. This work was supported by the Korea Ministry of Environment as "Climate Change Correspondence Program." We acknowledge the World Climate Research Programme's Working Group on Coupled Modelling, which is responsible for CMIP, and we thank the climate modeling groups (listed in Table 1 of this paper) for producing and making available their model output.

\section{REFERENCES}

Allen, R. J., and O. Ajoku, 2016: Future aerosol reductions and widening of the northern tropical belt. J. Geophys. Res. Atmos., 121, 6765-6786, https://doi.org/10.1002/2016JD024803.

, S. C. Sherwood, J. R. Norris, and C. S. Zender, 2012: Recent Northern Hemisphere tropical expansion primarily driven by black carbon and tropospheric ozone. Nature, 485, 350-354, https://doi.org/10.1038/nature11097.

_ J. R. Norris, and M. Kovilakam, 2014: Influence of anthropogenic aerosols and the Pacific decadal oscillation on tropical belt width. Nat. Geosci., 7, 270-274, https://doi.org/10.1038/ ngeo2091.

Barnes, E. A., and L. Polvani, 2013: Response of the midlatitude jets, and of their variability, to increased greenhouse gases in the CMIP5 models. J. Climate, 26, 7117-7135, https://doi.org/ 10.1175/JCLI-D-12-00536.1.

Braconnot, P., and Coauthors, 2007: Results of PMIP2 coupled simulations of the Mid-Holocene and Last Glacial MaximumPart 1: Experiments and large-scale features. Climate Past, 3, 261-277, https://doi.org/10.5194/cp-3-261-2007.

—, S. P. Harrison, M. Kageyama, P. J. Bartlein, V. MassonDelmotte, A. Abe-Ouchi, B. Otto-Bliesner, and Y. Zhao, 2012: Evaluation of climate models using palaeoclimatic data. Nat. Climate Change, 2, 417-424, https://doi.org/10.1038/ nclimate1456.

Chavaillaz, Y., F. Codron, and M. Kageyama, 2013: Southern westerlies in LGM and future (RCP4.5) climates. Climate Past, 9, 517-524, https://doi.org/10.5194/cp-9-517-2013.

Choi, J., S.-W. Son, J. Lu, and S.-K. Min, 2014: Further observational evidence of Hadley cell widening in the Southern Hemisphere. Geophys. Res. Lett., 41, 2590-2597, https://doi.org/10.1002/ 2014GL059426. 
Davis, N. A., and T. Birner, 2017: On the discrepancies in tropical belt expansion between reanalyses and climate models and among tropical belt width metrics. J. Climate, 30, 1211-1231, https://doi.org/10.1175/JCLI-D-16-0371.1.

Davis, S. M., and K. H. Rosenlof, 2012: A multidiagnostic intercomparison of tropical-width time series using reanalyses and satellite observations. J. Climate, 25, 1061-1078, https:// doi.org/10.1175/JCLI-D-11-00127.1.

Dee, D. P., and Coauthors, 2011: The ERA-Interim reanalysis: Configuration and performance of the data assimilation system. Quart. J. Roy. Meteor. Soc., 137, 553-597, https://doi.org/ 10.1002/qj.828.

Ebita, A., and Coauthors, 2011: The Japanese 55-year reanalysis "JRA-55": An interim report. SOLA, 7, 149-152, https:// doi.org/10.2151/sola.2011-038.

Frierson, D. M. W., J. Lu, and G. Chen, 2007: The width of the Hadley cell in simple and comprehensive general circulation models. Geophys. Res. Lett., 34, L18804, https://doi.org/ 10.1029/2007GL031115.

Garfinkel, C. I., D. W. Waugh, and L. M. Polvani, 2015: Recent Hadley cell expansion: The role of internal atmospheric variability in reconciling modeled and observed trends. Geophys. Res. Lett., $\mathbf{4 2}$, 10 824-10 831, https://doi.org/10.1002/2015GL066942.

Gerber, E. P., and S.-W. Son, 2014: Quantifying the summertime response of the austral jet stream and Hadley cell to stratospheric ozone and greenhouse gases. J. Climate, 27, 5538-5559, https://doi.org/10.1175/JCLI-D-13-00539.1.

Grise, K. M., and L. M. Polvani, 2016: Is climate sensitivity related to dynamical sensitivity? J. Geophys. Res. Atmos., 121, 51595176, https://doi.org/10.1002/2015JD024687.

Held, I. M., 2001: The general circulation of the atmosphere: 2000 program of study in geophysical fluid dynamics. Woods Hole Oceanographic Institution Tech. Rep. WHOI-2001-03, 181 pp., https://darchive.mblwhoilibrary.org/handle/1912/15.

_- and A. Y. Hou, 1980: Nonlinear axially symmetric circulations in a nearly inviscid atmosphere. J. Atmos. Sci., 37, 515-533, https://doi.org/10.1175/1520-0469(1980)037<0515: NASCIA $>2.0 . \mathrm{CO} ; 2$.

$\mathrm{Hu}$, Y., L. J. Tao, and J. P. Liu, 2013: Poleward expansion of the Hadley circulation in CMIP5 simulations. Adv. Atmos. Sci., 30, 790-795, https://doi.org/10.1007/s00376-012-2187-4.

IPCC, 2013: Climate Change, 2013: The Physical Science Basis. Cambridge University Press, 1535 pp., https://doi.org/10.1017/ CBO9781107415324.

Johanson, C. M., and Q. Fu, 2009: Hadley cell widening: Model simulations versus observations. J. Climate, 22, 2713-2725, https://doi.org/10.1175/2008JCLI2620.1.

Kalnay, E., and Coauthors, 1996: The NCEP/NCAR 40-Year Reanalysis Project. Bull. Amer. Meteor. Soc., 77, 437-471, https:// doi.org/10.1175/1520-0477(1996)077<0437:TNYRP>2.0.CO;2.

Kidston, J., and E. P. Gerber, 2010: Intermodel variability of the poleward shift of the austral jet stream in the CMIP3 integrations linked to biases in 20th century climatology. Geophys. Res. Lett., 37, L09708, https://doi.org/10.1029/ 2010 GL042873.

Kim, H.-K., and S. Lee, 2001: Hadley cell dynamics in a primitive equation model. Part II: Nonaxisymmetric flow. J. Atmos. Sci., 58, 2859-2871, https://doi.org/10.1175/ 1520-0469(2001)058<2859:HCDIAP > 2.0.CO;2.

Lau, W. K. M., and K.-M. Kim, 2015: Robust Hadley circulation changes and increasing global dryness due to $\mathrm{CO}_{2}$ warming from CMIP5 model projections. Proc. Natl. Acad. Sci. USA, 112, 3630-3635, https://doi.org/10.1073/pnas.1418682112.
Lu, J., G. A. Vecchi, and T. Reichler, 2007: Expansion of the Hadley cell under global warming. Geophys. Res. Lett., 34, L06805, https://doi.org/10.1029/2006GL028443.

- G. Chen, and D. M. W. Frierson, 2008: Response of the zonal mean atmospheric circulation to El Niño versus global warming. J. Climate, 21, 5835-5851, https://doi.org/10.1175/ 2008JCLI2200.1.

Lucas, C., B. Timbal, and H. Nguyen, 2014: The expanding tropics: A critical assessment of the observational and modeling studies. Wiley Interdiscip. Rev.: Climate Change, 5, 89-112, https://doi.org/10.1002/wcc.251.

Mantsis, D. F., S. Sherwood, R. Allen, and L. Shi, 2017: Natural variations of tropical width and recent trends. Geophys. Res. Lett., 44, 3825-3832, https://doi.org/10.1002/ 2016 GL072097.

Meehl, G. A., C. Covey, K. E. Taylor, T. Delworth, R. J. Stouffer, M. Latif, B. McAvaney, and J. F. B. Mitchell, 2007: THE WCRP CMIP3 multimodel dataset: A new era in climate change research. Bull. Amer. Meteor. Soc., 88, 1383-1394, https://doi.org/10.1175/BAMS-88-9-1383.

Meinshausen, M., and Coauthors, 2011: The RCP greenhouse gas concentrations and their extensions from 1765 to 2300 . Climatic Change, 109, 213-241, https://doi.org/10.1007/s10584-011-0156-z.

Min, S.-K., and S.-W. Son, 2013: Multimodel attribution of the Southern Hemisphere Hadley cell widening: Major role of ozone depletion. J. Geophys. Res. Atmos., 118, 3007-3015, https://doi.org/10.1002/jgrd.50232.

Nguyen, H., A. Evans, C. Lucas, I. Smith, and B. Timbal, 2013: The Hadley circulation in reanalyses: Climatology, variability, and change. J. Climate, 26, 3357-3376, https://doi.org/10.1175/ JCLI-D-12-00224.1.

Otto-Bliesner, B. L., and A. Clement, 2004: The sensitivity of the Hadley circulation to past and future forcings in two climate models. The Hadley Circulation: Present, Past and Future, H. F. Diaz and R. S. Bradley, Eds., Kluwer Academic Publishers, 437-464.

Phillips, N. A., 1954: Energy transformations and meridional circulations associated with simple baroclinic waves in a two-level, quasi-geostrophic model. Tellus, 6, 273-286, https://doi.org/ 10.1111/j.2153-3490.1954.tb01123.x.

Quan, X.-W., M. P. Hoerling, J. Perlwitz, H. F. Diaz, and T. Xu, 2014: How fast are the tropics expanding? J. Climate, 27, 19992013, https://doi.org/10.1175/JCLI-D-13-00287.1.

Rind, D., and J. Perlwitz, 2004: The response of the Hadley circulation to climate changes, past and future. The Hadley Circulation: Present, Past and Future, H. F. Diaz and R. S. Bradley, Eds., Kluwer Academic Publishers, 399-435.

Rojas, M., 2013: Sensitivity of Southern Hemisphere circulation to LGM and $4 \times$ CO2 climates. Geophys. Res. Lett., 40, 965-970, https://doi.org/10.1002/grl.50195.

Schneider, E. K., 1977: Axially symmetric steady-state models of the basic state for instability and climate studies. Part II. Nonlinear calculations. J. Atmos. Sci., 34, 280-296, https://doi.org/10.1175/ 1520-0469(1977)034<0280:ASSSMO>2.0.CO;2.

Schneider, T., and S. Bordoni, 2008: Eddy-mediated regime transitions in the seasonal cycle of a Hadley circulation and implications for monsoon dynamics. J. Atmos. Sci., 65, 915-934, https://doi.org/10.1175/2007JAS2415.1.

Seidel, D. J., Q. Fu, W. J. Randel, and T. J. Reichler, 2008: Widening of the tropical belt in a changing climate. Nat. Geosci., 1, 21-24, https://doi.org/10.1038/ngeo.2007.38.

Seo, J., S. M. Kang, and D. M. W. Frierson, 2014: Sensitivity of intertropical convergence zone movement to the latitudinal 
position of thermal forcing. J. Climate, 27, 3035-3042, https:// doi.org/10.1175/JCLI-D-13-00691.1.

Simmons, A. J., and B. J. Hoskins, 1978: The life cycles of some nonlinear baroclinic waves. J. Atmos. Sci., 35, 414-432, https:// doi.org/10.1175/1520-0469(1978)035<0414:TLCOSN >2.0.CO;2.

Solomon, A., L. M. Polvani, D. W. Waugh, and S. M. Davis, 2016: Contrasting upper and lower atmospheric metrics of tropical expansion in the Southern Hemisphere. Geophys. Res. Lett. 43, 10 496-10 503, https://doi.org/10.1002/2016GL070917.

Son, S.-W., and Coauthors, 2009a: The impact of stratospheric ozone recovery on tropopause height trends. J. Climate, 22 429-445, https://doi.org/10.1175/2008JCLI2215.1.

- N. F. Tandon, L. M. Polvani, and D. W. Waugh, 2009b: Ozone hole and Southern Hemisphere climate change. Geophys. Res. Lett., 36, L15705, https://doi.org/10.1029/ 2009 GL038671.

, and Coauthors, 2010: Impact of stratospheric ozone on Southern Hemisphere circulation changes: A multimodel assessment. J. Geophys. Res., 115, D00M07, https://doi.org/ 10.1029/2010JD014271.
Stachnik, J. P., and C. Schumacher, 2011: A comparison of the Hadley circulation in modern reanalyses. J. Geophys. Res., 116, D22102, https://doi.org/10.1029/2011JD016677.

Tao, L., Y. Hu, and J. Liu, 2016: Anthropogenic forcing on the Hadley circulation in CMIP5 simulations. Climate Dyn., 46, 3337-3350, https://doi.org/10.1007/s00382-015-2772-1.

Taylor, K. E., R. J. Stouffer, and G. A. Meehl, 2012: An overview of CMIP5 and the experiment design. Bull. Amer. Meteor. Soc., 93, 485-498, https://doi.org/10.1175/BAMS-D-11-00094.1.

Vallis, G. K., P. Zurita-Gotor, C. Cairns, and J. Kidston, 2015: Response of the large-scale structure of the atmosphere to global warming. Quart. J. Roy. Meteor. Soc., 141, 1479-1501, https://doi.org/10.1002/qj.2456.

Walker, C. C., and T. Schneider, 2006: Eddy influences on Hadley circulations: Simulations with an idealized GCM. J. Atmos. Sci., 63, 3333-3350, https://doi.org/10.1175/JAS3821.1.

Wilcox, L. J., A. J. Charlton-Perez, and L. J. Gray, 2012: Trends in austral jet position in ensembles of high- and low-top CMIP5 models. J. Geophys. Res., 117, D13115, https://doi.org/10.1029/ 2012JD017597. 